\title{
The prevalence of haemochromatosis gene mutations in the $W$ est of Scotland and their relation to ischaemic heart disease
}

\author{
S Campbell, D K George, S D Robb, R Spooner, T A McDonagh, H J Dargie, P R Mills
}

Heart 2003;89:1023-1026

See end of article for authors' affiliations

Correspondence to: Dr P R M ills, Floor 8 , $G$ artnavel $G$ eneral Hospital, $1053 \mathrm{G}$ reat W estern Road, G lasgow G 12 OYN, UK:

p.r.mills@clinmed.gla.ac.uk

Accepted 19 May 2003

\begin{abstract}
Objectives: Excess iron stores have been postulated to enhance the risk of ischaemic heart disease. This study aims to determine whether the two major mutations of the haemochromatosis (HFE) gene (C282Y and H63D) are associated with ischaemic heart disease (IHD) or myocardial infarction (MI). Design: Cross sectional case-control study.

Setting: The geographical area studied by the MONICA (monitoring trends and determinants in cardiovascular disease) heart attack register for N orth G lasgow in Scotland, UK.

Patients: 1009 control subjects chosen at random from general practitioner registers were studied. Additionally, 924 subjects who had survived a first M I sustained between 1985 and 1992 were identified from the MON ICA register.

Main outcome measures: $\mathrm{C} 282 \mathrm{Y}$ and $\mathrm{H} 63 \mathrm{D}$ mutations, previous $\mathrm{MI}$, and presence or absence of IHD.

Results: Mutant gene prevalences in the whole control population were as follows: C282Y: homozygote $0.9 \%$, heterozygote $17.7 \%$; H63D: homozygote $2.1 \%$, heterozygote $25.5 \%$; and compound heterozygote: $2.4 \%$. A nalysis by $\chi^{2}$ test and logistic regression analysis did not identify any significant difference in genotype prevalence between normal control, IHD control, and MI survivor groups.

Conclusions: The $\mathrm{C} 282 \mathrm{Y}$ homozygote and heterozygote prevalences are among the highest reported worldwide. No association between IHD or MI and HFE genotype was identified. However, these results need to be interpreted in the light of the cross sectional case-control nature of the study.
\end{abstract}

he accumulation of excess iron stores has been postulated to enhance the risk of ischaemic heart disease (IHD) ${ }^{1}$ by increasing atherogenesis or by augmenting ischaemic myocardial injury. However, results of studies examining the association between iron stores and IHD have been conflicting. . $^{2-5}$

Hereditary haemochromatosis is now recognised as one of the most common autosomal recessive genetic disorders in populations of European descent. ${ }^{6}$ Two major missense mutations of the haemochromatosis (HFE) gene are responsible for the vast majority of cases of hereditary haemochromatosis. ${ }^{7}$ Homozygosity for the C282Y mutation was responsible for $91 \%$ of cases of hereditary haemochromatosis in a small study of the population of the $\mathrm{UK}^{8}$ and the combination of a C282Y mutant allele and a H63D mutant allele (so-called compound heterozygosity) may be responsible for a further 3-5\%. ${ }^{8}$ When present in the heterozygous (carrier) state, these mutations are also associated with an increase in markers of iron storage, although this increase is modest and is usually readily apparent only in large population studies. ${ }^{10}$ Results of studies that have addressed the association between HFE genotype and IHD or vascular disease have been conflicting. ${ }^{11-16}$

Scotland is an area of high prevalence of IHD, and small studies of populations of mainly Celtic origin have suggested that the prevalence of the C282Y mutation may be high, ${ }^{6}{ }^{17}$ making this population an ideal one in which to look for an association.

Our aim was to determine the prevalence of the common HFE gene mutations in a west of Scotland control population and in a post-myocardial infarction (MI) population, and to determine whether these mutations are associated with IHD or MI.

\section{SUBJ ECTS AND METHODS}

Subjects

A random sample of 1688 subjects aged between 55 and 74 years and living in North Glasgow, Scotland, UK were identified from the patient registers of local general medical practitioners, with the intention of identifying the prevalence of cardiac disease in this population by a two stage, stratified randomisation process. All had to reside within the geographical area previously defined by the World Health Organization's Scottish MONICA (monitoring trends and determinants in cardiovascular disease) heart attack register for North Glasgow project-that is, within the boundaries of the city of Glasgow north of the River Clyde. ${ }^{18}$ It was our intention to recruit a study cohort of 1000 subjects, by oversampling where necessary, and stratified such that there would be a target of 125 men and 125 women within each five year age band. Subjects were excluded if they had a history of severe mental or physical disease that would limit their ability to provide consent or to attend appointments.

These subjects were invited for a clinic visit to provide a detailed medical history and for a physical examination, ECG, and blood sampling. The 12 lead ECG was recorded in a standard fashion at a paper speed of $25 \mathrm{~mm} / \mathrm{s}$ and subsequently coded according to the M innesota ECG code ${ }^{19}$ for the presence of Q/QS waves (1.1-1.3), left bundle branch block (7.11), ST segment depression (4.1-4.4), and T wave inversion (5.1-5.3). This study achieved a response rate of $59.8 \%$, with 1009 participants attending. Blood samples were obtained

Abbreviations: HFE, haemochromatosis gene; IHD, ischaemic heart disease; MI, myocardial infarction; MON ICA, monitoring trends and determinants in cardiovascular disease 
Table 1 Characteristics of the three subject groups

\begin{tabular}{|c|c|c|c|c|c|}
\hline & $\begin{array}{l}\text { Normal control } \\
(n=493)\end{array}$ & $\begin{array}{l}\text { IHD control } \\
(n=427)\end{array}$ & $\begin{array}{l}\text { MI survivor } \\
(n=828)\end{array}$ & $\begin{array}{l}\text { Normal control v } \\
\text { IHD control OR }(95 \% \mathrm{CI})\end{array}$ & $\begin{array}{l}\text { Normal control v } \\
\text { MI survivor OR }(95 \% \mathrm{Cl})\end{array}$ \\
\hline Men & $251(51 \%)$ & $217(51 \%)$ & $606(73 \%)$ & $0.99(0.75$ to 1.3$)$ & $2.57(1.93 \text { to } 3.43)^{*}$ \\
\hline M ean (SD) age (years) & $65(5)$ & $65(6)$ & $61(7)$ & $1.0(0.98$ to 1.0$)$ & $0.91(0.89$ to 0.93$) *$ \\
\hline Diabetes & $34(6.9 \%)$ & $26(6.1 \%)$ & $92(11 \%)$ & $0.87(0.51$ to 1.5$)$ & $1.46(0.90$ to 2.4$)$ \\
\hline Current smokers & $47(9.5 \%)$ & $39(9.1 \%)$ & $281(34 \%)$ & $0.97(0.60$ to 1.6$)$ & $6.36(4.1 \text { to } 9.8)^{*}$ \\
\hline Former smokers & $297(60 \%)$ & $260(61 \%)$ & $378(46 \%)$ & $1.0(0.76$ to 1.4$)$ & $1.38(0.99$ to 1.9$)$ \\
\hline Hypertension & $328(66 \%)$ & $289(68 \%)$ & $399(48 \%)$ & $1.0(0.71$ to 1.3$)$ & $0.57(0.44$ to 0.75$) *$ \\
\hline M ean (SD) cholesterol (mmol/ I) & $5.97(1.1)$ & $5.97(1.1)$ & $5.97(1.1)$ & $0.99(0.88$ to 1.1$)$ & $1.04(0.92$ to 1.18$)$ \\
\hline ECG criteria for LVH & $80(16 \%)$ & $63(15 \%)$ & $89(11 \%)$ & $0.86(0.59$ to 1.2$)$ & $0.62(0.42 \text { to } 0.94)^{*}$ \\
\hline
\end{tabular}

from 962 subjects. The response rate was higher for men than for women $(63.1 \% \vee 56.8 \%, p=0.008)$ and was higher in the first 10 years of the age range than in the second $(64.7 \% \mathrm{~V}$ $55.4 \%, p<0.001)$. The subjects who had any evidence of current or previous IHD (MI, angina pectoris, coronary revascularisation procedure, or the ECG abnormalities described above) identified from the medical history, physical examination, or ECG were placed into a group denoted "IHD controls". The remaining subjects, who had no evidence of IHD, were placed into a group denoted "normal controls".

Nine hundred and twenty four subjects who had sustained a first validated $\mathrm{MI}$ and who attended a follow up visit were identified from the MONICA register. The MONICA project maintains a database of all coronary events in selected populations. The Glasgow MONICA project identifies all people resident in North Glasgow aged between 25 and 64 years at the time of MI on the basis of hospital discharge coding, death certificate data from the Registrar General for Scotland, and postmortem and general practitioner data. ${ }^{18}$ Two thousand, two hundred and fifty eight people were initially identified from the register as having survived a first M I between 1985 and 1992. Five hundred and fifty six (24.6\%) had died, 170 (7.5\%) had moved out of the area, 82 (3.6\%) were within the practices of a general practitioner not participating in the study, and 63 (2.8\%) were excluded by their general practitioner as being unable to attend because of severe mental or physical disease. The response rate within this eligible group was therefore $66.6 \%$.

All of these remaining subjects had therefore survived M I for a median period of 7.0 years ( range $2.5-11.5$ years). Stored blood, which had been sampled in 1995-96, was available for 846 of these subjects. This group of subjects was denoted " M I survivors".

All subjects gave written informed consent to the use of their blood for genetic analysis, and this study conforms to the principles of the Declaration of Helsinki. This study was approved by the local hospital ethics committee.

\section{Laboratory analysis}

Venous blood samples were analysed for the C282Y and H63D mutations by standard restriction fragment length polymorphism techniques following amplification by polymerase chain reaction. ${ }^{7}$ These mutations are, with very rare exceptions, ${ }^{20}$ mutually exclusive on the same chromosome (that is, they are in complete linkage disequilibrium), allowing the subjects to be classified into six genotypes. These genotypes are: wild type ( $\mathrm{H} 63 \mathrm{H}, \mathrm{C} 282 \mathrm{C} / \mathrm{H} 63 \mathrm{H}, \mathrm{C} 282 \mathrm{C}), \mathrm{H} 63 \mathrm{D}$ homozygote (H63D, C282C/ H63D, C282C), H63D heterozygote (H63D, C282C/ H63H, C282C), compound heterozygote (H63D, C282C/ H63H, C282Y), C282Y homozygote $(\mathrm{H} 63 \mathrm{H}$, $\mathrm{C} 282 \mathrm{Y} / \mathrm{H} 63 \mathrm{H}, \mathrm{C} 282 \mathrm{Y})$, and $\mathrm{C} 282 \mathrm{Y}$ heterozygote $(\mathrm{H} 63 \mathrm{H}$, $\mathrm{C} 282 \mathrm{Y} / \mathrm{H} 63 \mathrm{H}, \mathrm{C} 282 \mathrm{C}$ ). For logistical reasons, or because of an inadequate sample of blood, genetic analysis was incomplete for 60 (3.3\%) of the 1808 subjects from whom blood had been obtained ( 26 (5.0\%) normal controls, 16 (3.6\%) IHD controls, and 18 (2.1\%) MI survivors).

\section{Statistical analysis}

The Hardy-Weinberg equation ${ }^{21}$ and the $\chi^{2}$ goodness of fit test were used to test for genetic equilibrium. The difference in genotype frequencies between groups (univariate analysis) was compared using the $\chi^{2}$ test or Fisher's exact test, where appropriate, and by using logistic regression analysis (multivariate analysis) to correct for differences in age, sex, and other IHD risk factors. One way analysis of variance was used to compare the means of continuous variables. The $95 \%$ confidence interval $(\mathrm{Cl})$ of an estimate of prevalence was cal culated by the method described by Bland. ${ }^{22}$ Significance was taken as being $p<0.05$. All analyses were two tailed. Analyses were performed using SPSS statistical software, version 10 (SPSS Inc, Chicago, Illinois, USA).

\section{RESULTS}

Table 1 shows the number of subjects in each of the three groups (normal control, IHD control, and MI survivor), together with a breakdown of age, sex, and other IHD risk factors. There was a significant difference, by univariate analysis, between the normal control group and the MI survivor group for all variables ( $p<0.01$ ), with the exception of mean serum cholesterol concentration and the proportion of subjects who were diabetic, or were former smokers. Table 1 also shows the odds ratio for each risk factor. There was no difference in age, sex, or other IHD risk factors between the normal control and IHD control group. The overall prevalence of IHD in the entire control group was $46 \%$. This was subdivided as follows: ECG evidence of previous MI (Q/QS waves) 6.6\%; left bundle branch block, ST segment depression, or T wave inversion 26.6\%; antianginal treatment 9.9\%; self reported history of $\mathrm{MI} 10.7 \%$; and self reported history of angina $16.4 \%$ (note that subjects could be included in more than one category).

Table 2 shows the frequencies in the whole control population (normal controls and IHD controls) of the H63D and C282Y homozygotes, heterozygote carriers, compound heterozygotes, and individual allele frequencies. The distributions of these genotypes were all in Hardy-Weinberg equilibrium ( $p=0.24, p=0.74, p=0.79$, for wild type, H63D, and C282Y, respectively).

Table 3 shows the prevalence of each of the six possible genotypes for each subject group. This table also shows the odds ratios and $95 \% \mathrm{Cls}$ by logistic regression analysis comparing the normal control versus IHD control and normal control versus MI survivor groups, respectively. There was no significant difference in the genotype frequencies (as assessed by univariate analysis) between the groups with the exception of the C282Y heterozygotes, which occurred less frequently in the post-MI group than in the normal control group $(p=0.04)$. After correction for differences between the two 
Table 2 Allele and genotype frequencies (\%) in the whole control population of 920 patients

\begin{tabular}{|c|c|c|c|c|}
\hline & $\begin{array}{l}\text { Homozygote } \\
(95 \% \text { CI) }\end{array}$ & $\begin{array}{l}\text { Heterozygote } \\
(95 \% \mathrm{Cl})\end{array}$ & $\begin{array}{l}\text { Compound heterozygote } \\
(95 \% \mathrm{Cl})\end{array}$ & $\begin{array}{l}\text { Allele frequency } \\
(95 \% \mathrm{Cl})\end{array}$ \\
\hline $\begin{array}{l}\text { H63D } \\
\text { C282Y } \\
\text { W ild type }\end{array}$ & $\begin{array}{ll}2.06 & (1.15 \text { to } 2.98) \\
0.87 & (0.27 \text { to } 1.47)\end{array}$ & $\begin{array}{l}25.54 \text { (22.73 to } 28.36) \\
17.72 \text { (15.25 to } 20.18)\end{array}$ & 2.39 (1.40 to 3.38$)$ & $\begin{array}{l}14.84 \text { (12.54 to } 17.13) \\
9.73 \text { (7.81 to } 11.64) \\
75.43 \text { (72.65 to } 78.22)\end{array}$ \\
\hline
\end{tabular}

Table 3 Prevalence of the possible HFE genotypes in each subject group

\begin{tabular}{llllll}
\hline & $\begin{array}{l}\text { Normal control } \\
(n=493)\end{array}$ & $\begin{array}{l}\text { IHD control } \\
(n=427)\end{array}$ & $\begin{array}{l}\text { MI survivor } \\
(n=828)\end{array}$ & $\begin{array}{l}\text { Normal control v IHD } \\
\text { control OR }(95 \% \mathrm{CI})\end{array}$ & $\begin{array}{l}\text { Normal control v } \\
\mathrm{MI} \text { survivor OR (95\% CI) }\end{array}$ \\
\hline W ild type & $268(54.4 \%)$ & $249(58.3 \%)$ & $468(56.5 \%)$ & $1.17(0.90$ to 1.5$)$ & $1.14(0.87$ to 1.5$)$ \\
H63D homozygote & $10(2.0 \%)$ & $9(2.1 \%)$ & $23(2.8 \%)$ & $1.02(0.41$ to 2.6$)$ & $1.22(0.51$ to 2.9$)$ \\
H63D heterozygote & $115(23.3 \%)$ & $98(23.0 \%)$ & $198(23.9 \%)$ & $0.97(0.71$ to 1.3$)$ & $1.04(0.76$ to 1.4$)$ \\
Compound heterozygote & $15(3.0 \%)$ & $7(1.6 \%)$ & $31(3.7 \%)$ & $0.53(0.21$ to 1.3$)$ & $0.87(0.42$ to 1.8$)$ \\
C282Y homozygote & $5(1.0 \%)$ & $3(0.7 \%)$ & $7(0.8 \%)$ & $0.71(0.17$ to 3.0$)$ & $1.20(0.23$ to 6.2$)$ \\
C282Y heterozygote & $80(16.2 \%)$ & $61(14.3 \%)$ & $101(12.2 \%)$ & $0.88(0.61$ to 1.3$)$ & $0.70(0.48$ to 1.04$)$ \\
\hline
\end{tabular}

$\mathrm{N}$ one of the genotype groups achieved significance.

HFE, ha emochromatosis gene.

groups using logistic regression, there were no significant associations. In particular, the lower frequency of C282Y heterozygotes in the MI survivors than in the control group became insignificant (odds ratio $0.70,95 \% \mathrm{Cl} 0.48$ to 1.04 , $p=0.08)$. Analysis of men and women separately did not show any significant associations, with the exception of the lower frequency of C282Y heterozygotes in the MI survivors than in the control group, which was confined to women only. This negative association in women between the MI survivor group and C282Y heterozygosity persisted on multivariate analysis (odds ratio $0.51,95 \% \mathrm{Cl} 0.27$ to $0.98, \mathrm{p}=0.04$ ) .

\section{DISCUSSION}

This is the largest study to date of the prevalence of the HFE gene mutations in a randomly selected mainland UK or I rish population. The $\mathrm{C} 282 \mathrm{Y}$ heterozygote and homozygote frequencies were higher in this study than in any other study of the mainland UK population, ${ }^{68}$ are comparable with frequencies found in studies of the Irish population, ${ }^{17}$ and are among the highest reported frequencies of any study worldwide. This study also confirmed our expectations that the west of Scotland is an area of high prevalence of IHD. Although this population sample does not include the extremes of age, we felt that the gene frequencies were still likely to be a reasonable estimate of those in the overall population. We did not detect any change in the frequency of the HFE gene mutations with increasing age cohorts (for example, of 5 or 10 years) in the population studied (data not shown)

The "iron hypothesis" proposes that increased iron stores lead to an increase in the risk of IHD. ${ }^{1}$ This may account for the higher incidence of IHD in men and postmenopausal women than in premenopausal women. As iron stores increase with age in both sexes, the iron hypothesis may al so account for the increasing incidence of IHD with aging. I ron is a pro-oxidant and can increase the peroxidation of low density lipoprotein, which may promote atherogenesis. It may also promote IHD by augmenting free radical mediated myocardial damage occurring after an ischaemic event. This effect, in theory, is independent but additive to any effect on atherogenesis. The iron hypothesis also proposes that iron depletion may protect against or decrease the severity of ischaemic coronary events.

In the absence of randomised controlled studies of iron depletion in normal populations, evidence to support the iron hypothesis has been sought from biochemical studies of iron stores and, with the discovery of the major mutations associated with haemochromatosis in 1996, ${ }^{7}$ from studies of the HFE genotype.
Results of studies of iron stores have been conflicting. Biochemical measurement of iron status is prone to interference by multiple factors such as inflammation, recent blood loss, and medication. An early study from Finland showed a positive association between iron stores and IHD, ${ }^{2}$ but further large studies ${ }^{34}$ and a meta-analysis of all prospective studies ${ }^{5}$ have been negative.

Genotype studies are unaffected by the factors discussed above, although these have also shown conflicting results. Cross sectional case-control studies ${ }^{14-162324}$ have had similar findings to our own, namely no association between IHD and HFE genotype. The study by Hetet and colleagues ${ }^{15}$ is of particular note, as it showed an association between C282Y heterozygosity and IHD in a subset analysis of women from the same geographical population as that of our study. Analysis of women as a separate subset from our data suggested the opposite. We found a non-significant trend towards a negative association between IHD and C282Y heterozygosity.

Three prospective studies have addressed the association between HFE genotype and IHD. The Utrecht study ${ }^{11}$ showed a non-significant increased relative risk (approximately 2 ) for MI in postmenopausal women that was associated with C282Y heterozygosity but a significantly increased relative risk for all cardiovascular death. The Finnish ${ }^{12}$ and US $^{13}$ studies also showed a non-significant increased relative risk of similar magnitude. However, after correction for other risk factors, a significantly increased relative risk was found (between approximately 2 and 3 ). These three studies did not consider the H63D mutation.

Our study had a cross sectional case-control design and therefore identified only surviving members of the population. In particular, the post-M I group had all survived between 2-11 years after MI. A survival disadvantage may explain why the prevalences of left ventricular hypertrophy and hypertension were lower in the M I survival group. If the HFE mutations confer a survival disadvantage to those with IHD or MI, then differences in genotype prevalence apparent in prospective studies may not be detected in a cross sectional case-control study. It is theoretically possible therefore that the one genotype to show a trend towards a differing prevalence between groups (albeit losing significance after adjustment for risk factors or multiple significance testing), namely the lower frequency of C282Y heterozygotes in the M I survivor group, may confer a survival disadvantage related to iron stores following MI. 


\section{Conclusion}

The C282Y homozygote and heterozygote prevalence in this West of Scotland population is among the highest reported worldwide. There was no association between IHD or MI and HFE genotype in this large study despite a high prevalence of IHD. However, these results need to be interpreted in the light of the cross sectional case-control nature of our study.

\section{ACKNOWLEDGEMENTS}

The authors are grateful to the Haemochromatosis Society for a grant to conduct this study.

Authors' affiliations

S Campbell, P R Mills, Department of $\mathrm{G}$ astroenterology, $\mathrm{G}$ artnavel G eneral Hospital, G lasgow, UK

D K George, Department of G astroenterology, Torbay Hospital, Devon, UK

S D Robb, H J Dargie, Department of Cardiology, W estern Infirmary, Glasgow

R Spooner, Department of Biochemistry, G artnavel G eneral Hospital,

Glasgow

TA McDonagh, Department of Cardiology, Royal Infirmary, G lasgow

\section{REFERENCES}

1 Sullivan JL. Hypothesis: iron and the sex difference in heart disease risk. Lancet 1981:i:1293-4.

2 Salonen JT, N yyssonen $\mathrm{K}$, Korpela $\mathrm{H}$, et al. High stored iron levels are associated with excess risk of myocardial infarction in eastern Finnish men. Circulation 1992;86:803-11.

3 Sempos CT, Looker AC, Gillum RF, et al. Serum ferritin and death from all causes and cardiovascular disease. The N HAN ES II mortality study. Ann Epidemiol 2000;10:441-8

4 Sempos CT, Looker AC, Gillum RF, et al. Body iron stores and the risk of coronary heart disease. N EnglJ M ed 1994;330:1119-24.

5 Danesh J, A ppleby P. Coronary heart disease and iron status: meta-analyses of prospective studies. Circulation 2001:99:852-4.

6 Merryweather-Clarke AT, Pointon JJ, Shearman JD, et al. G lobal prevalence of putative haemochromatosis mutations. J Med G enet $1997 ; 34: 275-8$

7 Feder JN, G nirke A, Thomas W, et al. A novel M HC class I-like gene is mutated in patients with hereditary haemochromatosis. $N$ at $G$ enet $1996 ; 13: 399-408$
8 Anon. A simple genetic test identifies $90 \%$ of UK patients with ha emochromatosis. The UK Haemochromatosis Consortium. G ut 1997;41:841-4.

9 Miedzybrodzka Z, Loughlin S, Baty D, et al. Haemochromatosis mutations in N orth-East Scotland. Br J Haematol 1999;106:385-7.

10 Beutler E, Felitti V, G elbart T, et al. The effect of HFE genotypes on measurements of iron overload in patients attending a health appraisal clinic. Ann Intern Med 2000:133:329-37.

11 Roest M, Van der Schouw YT, de Valk B, et al. Heterozygosity for a hereditary haemochromatosis gene is associated with cardiovascular death in women. Circulation 1999;100:1268-73.

12 Tuomainen TP, Kontula K, N yyssonen K, et al. Increased risk of acute myocardial infarction in carriers of the hemochromatosis gene Cys2 $82 \mathrm{Tyr}$ mutation: a prospective cohort study in men in eastern Finland. Circulation 1999:100:1274-9.

13 Rasmussen ML, Folsom AR, Catellier DJ, et al. A prospective study of coronary heart disease and the hemochromatosis gene (HFE) C $282 \mathrm{Y}$ mutation: the atherosclerosis risk in communities (ARIC) study. A therosclerosis 2001;154:739-46.

14 Battiloro $\mathrm{E}, \mathrm{O}$ mbres D, Pascale $\mathrm{E}$, et al. Haemochromatosis gene mutations and risk of coronary artery disease. Eur J Hum G enet $2000: 8: 389-92$

15 Hetet G, Elbaz A, G ariepy J, et al. Association studies between hameochromatosis gene mutations and the risk of cardiovascular diseases. Eur J Clin Invest 2001;31:382-8.

16 Franco RF, Zago MA, Trip MD, et al. Prevalence of hereditary haemochromatosis in premature atherosclerotic vascular disease. $\mathrm{Br}$ J Haematol 1998;102:1172-5.

17 Byrnes V, Ryan E, Barrett S, et al. G enetic hemochromatosis, a C eltic disease: is it now time for population screening? G enet Test 2001;5:127-30

18 Tunstall-Pedoe $\mathrm{H}$, M orrison C, W oodward M, et al. Sex differences in myocardial infarction and coronary deaths in the Scottish MON ICA population of G lasgow 1985-1991: presentation, diagnosis, treatment, and 28-day case fatality of 2991 events in men and 1551 events in women Circulation 1996.93:1981-92.

19 Prineas RJ, Crow RS, Blackburn H. The Minnesota code manual of electrocardiographic findings. Bristol: John W right and Sons, 1982.

20 Thorstensen K, A sberg A, Kvitland $M$, et al. Detection of an unusual combination of mutations in the HFE gene for hemochromatosis. G enet Test 2000;4:371-6.

21 Hardy GH. Mendelian proportions in a mixed population. Science 1908:28:41-50.

22 Bland JM. An introduction to medical statistics, 2 nd ed. 0 xford: 0 xford University Press, 1995:8,125-6.

23 Calado RT, Franco RF, Pazin-Filho A, et al. HFE gene mutations in coronary atherothrombotic disease. Braz J M ed Biol Res 2000;33:301-6.

24 Nassar BA, Zayed EM, Title LM, et al. Relation of HFE gene mutations, high iron stores and early onset coronary artery disease. Can J Cardiol $1998 ; 14: 215-20$

Tel: $+44(0) 2073836409$

Fax: $+44(0) 2073836869$ 